\title{
Genetically Modified Rice Adoption: Implications for Welfare and Poverty Alleviation
}

\author{
Kym Anderson, Lee Ann Jackson and Chantal Pohl Nielsen ${ }^{* *}$
}

JEL codes: C68, D58, F13, O3, Q17, Q18

Key words: Biotechnology, GMOs, regulation, trade policy, computable general equilibrium

World Bank Policy Research Working Paper 3380, August 2004

The Policy Research Working Paper Series disseminates the findings of work in progress to encourage the exchange of ideas about development issues. An objective of the series is to get the findings out quickly, even if the presentations are less than fully polished. The papers carry the names of the authors and should be cited accordingly. The findings, interpretations, and conclusions expressed in this paper are entirely those of the authors. They do not necessarily represent the view of the World Bank, its Executive Directors, or the countries they represent. Policy Research Working Papers are available online at http://econ.worldbank.org.

\footnotetext{
** Anderson and Jackson were both at the University of Adelaide, Australia when preparing this paper, and Nielsen is with the Danish Research Institute of Food Economics in Copenhagen. Anderson is on leave with the Development Research Group of the World Bank in Washington DC and Jackson is now with the WTO Secretariat in Geneva. The views expressed are the authors' alone and not necessarily those of their current employers. Contact from 17 May is: kanderson@worldbank.org.
} 


\begin{abstract}
The first generation of genetically modified (GM) crop varieties sought to increase producer profitability through cost reductions or higher yields, while the next generation of GM food research is focusing on breeding for attributes of interest to consumers. "Golden Rice," for example, has been genetically engineered to contain a higher level of vitamin A and thereby boost the health of poor people in developing countries. This paper analyzes the potential economic effects of adopting both types of innovation in Asia, including its impact on rice producers and consumers. It does so using the global economy-wide computable general equilibrium model known as GTAP. The results suggest the farm productivity gains could be dwarfed by the welfare gains resulting from the potential health-enhancing attributes of golden rice, which would boost the productivity of unskilled workers among Asia's poor.
\end{abstract}

Key words: GMOs, golden rice, consumer preferences, nutritional attributes

JEL codes: C68, D58, F13, O3, Q17, Q18 


\section{Genetically Modified Rice Adoption: Implications for Welfare and Poverty Alleviation}

\section{Introduction}

In the late 1990s many producers of maize, soybean and canola in the United States, Canada, and Argentina embraced genetically modified (GM) varieties of these commodities. Typically this technology has conferred direct benefits to farmers through reduced input costs and/or improved management flexibility, and benefits to consumers via lower food prices. However, as public and private research expands, the next generation of GM crops promises to include GM varieties of various crops that also provide direct benefits to consumers through enhanced consumption characteristics such as improved nutritional content. Golden rice, a GM variety of rice that has been genetically modified to produce beta-carotene, is the most important imminent product to result from this research. It has the potential to improve health in regions where rice is or could be a dietary staple for poor people. If that development leads to a widespread acceptance of genetic modification of food crops in Asian and other developing countries, potential direct farm productivity gains of GM agricultural technology could be reaped there as well.

This paper uses a global computable general equilibrium (CGE) trade model to estimate the potential economic impacts of adoption of golden rice and other GM rice varieties in Asia. More specifically, it estimates the potential welfare gains from the consumer-focused health attribute of golden rice and compares them with the welfare benefits of producer-focused attributes of other new (non-golden) GM rice 
varieties. It thereby extends earlier empirical economic studies of adoption of GM varieties, which focus on the welfare effects only of direct farm productivity gains. It also estimates the welfare impact if GM adoption were to spread beyond rice to other grains and oilseeds, both in the absence and in the presence of richer countries choosing to ban food imports from GM-adopting countries. ${ }^{1}$ The consumer-focused health attribute of golden rice is reflected in improved productivity of unskilled farm and non-farm workers whose health would improve because of greater vitamin A intake.

The next section provides more details of the potential of golden and other GM rice varieties. In Section 3 we describe the GTAP (Global Trade Analysis Project) model of the global economy and methodology used to explore the potential impacts on rice markets, on national economic welfare, and on the real household incomes of farm families and of other unskilled workers in the affected developing countries. Results are presented in Section 4 for a range of scenarios that vary the set of adopting countries and the policy responses to GM rice. The paper concludes in Section 5 by stressing the potential distributional and poverty alleviation impacts of the adoption of GM rice (and other crop) varieties in Asia.

\section{Prospective impacts of GM rice on Asian farm and labor productivity}

The first generation of genetic engineering in agriculture has produced modified crops with improved agronomic traits, such as tolerance of specific chemical herbicides and resistance to pests and diseases (James 2003). The development of

\footnotetext{
${ }^{1}$ The motivation for such a ban could be genuine concern for food safety or the environment or simply because it provides a way to re-instrument economic protection for farmers in the wake of pressure to
} 
transgenic plants with enhanced agronomic traits aims at increasing farmer profitability, typically by increasing factor and input productivity. A second generation of genetic modification is now under way and is seeking also to improve various attributes of products to the direct benefit of the final consumer, such as enhanced nutritional content, improved durability, and better processing characteristics. Farmers would adopt this type of GM crop variety, even if it had no productivity benefits for them net the higher cost of seed and the cost of segregation and identity preservation, if they could sell these products at a higher market price. Higher prices could result from consumers' perceptions that it is a better product relative not only to the other GM varieties with improved farm productivity attributes, but also to non-GM varieties.

Golden rice is the most important imminent GM crop. Some GM rice varieties have the potential to boost farm productivity, with yields per hectare expected to be as much as 10 percent higher for 40 percent of global production within a decade, according to Brookes and Barfoot (2003, p. 48). Golden rice, however, is a GM variety that may not enhance farm productivity but could improve health significantly in regions where rice is or could be a dietary staple for poor people, through providing pro-vitamin A (Dawe, Robertson and Unnevehr 2002). Due to genetic modification, golden rice contains a higher level of beta-carotene, which is needed for the production of pro-vitamin $\mathrm{A}$, in the endosperm of the grain than non-modified rice. ${ }^{2}$ It has the potential to have long-term benefits for the poor in developing countries where chronic Vitamin A deficiency (VAD) leads to blindness, weakened immune systems, and increased morbidity and mortality for children and pregnant and

lower import tariffs. In the case of rice especially, the very high levels of tariff protection in Japan and Korea are under great pressure from other WTO members. 
lactating women. It is estimated that up to 0.5 million children suffering from VAD go blind every year, and nearly 0.6 million women die annually from childbirthrelated causes, many of them from complications which could be reduced through better provision of Vitamin A (Sommer and West 1996). Focusing on the potential direct health cost estimates using a disability-adjusted life year (DALY) approach, a recent study finds that introducing golden rice in the Philippines could decrease the number of DALYs lost due to VAD by between 6 and 47 percent (Zimmermann and Qaim 2003). ${ }^{3}$

The biotechnology firm Syngenta owns the rights to golden rice for commercialization. It is helping to transfer the technology to developing countries by complying with existing biosafety and environmental risk assessment laws/regulations and making the technology available free to farmers earning less than US\$10,000 a year from rice. Farmers will also be able to save seed from their initial crop for future plantings, rather than buy it every year (Brookes and Barfield 2003, p. 10; Zimmermann and Qaim 2002, p. 15).

As with the first-generation GM technology that focused on reducing producers' unit costs, the benefits of golden rice and other types of GM rice over time will be shared between producers and consumers, and hence between adopting and non-adopting countries. If countries remain or become more open to international trade in these products the potential benefits will increase. In 2001 only 6 percent of global rice production was traded internationally, but this represents an increase from 3.3 percent a decade earlier (FAOSTAT). Production is increasing as trade barriers are lowered following WTO and regional trade negotiation rounds. GM rice adoption

\footnotetext{
${ }^{2}$ See Ye et al. (2000) and Beyer et al. (2002). Beta-carotene does not occur naturally in the endosperm of rice, hence the need for genetic modification (Bouis 2000).
} 
could contribute to that trend - or could weaken it if some countries adopt the new technology and, in response, others ban rice imports from adopting countries (as analyzed below).

\section{Model methodology}

We use a well-received empirical model of the global economy (the GTAP model) to examine the effects of some countries adopting the new GM technology without and then with specific government and consumer responses in some other countries. Being a general equilibrium model, GTAP (Global Trade Analysis Project) describes both the vertical and horizontal linkages between all product markets both within the model's individual countries and regions as well as between countries and regions via their bilateral trade flows. The Version 5.4 database used for these applications draws on the global economic structures and trade flows of 1997, the time of the rapid adoption of GM crop varieties. To make the results easier to absorb, the GTAP model has been aggregated to depict the global economy as having 17 regions and 14 sectors (with the focus on the primary agricultural sectors affected by the GM debate and their related processing industries). ${ }^{4}$ We have undertaken further sectoral disaggregation of the database by separating golden rice and other GM crop varieties from non-GM varieties of rice, oilseeds, and coarse grains. There are five

\footnotetext{
${ }^{3}$ For more on the concept of estimating impacts in terms of disability-adjusted life years (DALYs), see Murray and Lopez (1996).

${ }^{4}$ The GTAP (Global Trade Analysis Project) model is a multi-regional, static, applied general equilibrium model based on neo-classical microeconomic theory assuming perfect competition, constant returns to scale and full employment of all productive factors which are immobile internationally. International goods and services trade is described by an Armington specification, which means that products are differentiated by country of origin. See Hertel (1997) for comprehensive model documentation and Dimaranan and McDougall (2002) for details of the GTAP 5.4 database used here. The model is solved with GEMPACK software (Harrison and Pearson 1996). Welfare decomposition follows Harrison, Horridge and Pearson (1999). Pervious uses of the GTAP model in
} 
types of productive factors in the version used here: skilled labor, unskilled labor, agricultural land, other natural resources, and other (non-human) capital. All factors except natural resources (which are specific to primary production) are assumed to be perfectly mobile throughout the national economy but immobile internationally.

We have modified the GTAP model so it can capture the effects of productivity increases of GM crops, consumer aversion to consuming GM products other than golden rice (for which a stronger preference rather than aversion is assumed in developing countries), and substitutability between GM and non-GM products as intermediate inputs into final consumable foods.

The simulations use a standard, long-run, neoclassical GTAP closure. This closure is characterized by perfect competition in all markets, flexible exchange rates and fixed endowments of labor, capital, land and natural resources. One outcome of this specification is that wages are flexible and the labor (and other factor) markets operate at full employment. In addition, investment funds are re-allocated among regions following a shock so as to return to equalized expected rates of return.

\section{Production}

Traditionally, to distinguish GM from non-GM productivity, the GM-adopting sectors are each sub-divided into GM and non-GM product, and an outputaugmenting, productivity shock is implemented on the GM varieties of these commodities to capture their higher productivity. This assumes that GM technology reduces the level of primary factors and some intermediate inputs needed per unit of output. When a region does not adopt GM technologies, no regional factor productivity shock is included and there is no distinction between GM and non-GM

assessing the economic implications of GM crop adoption include Nielsen and Anderson (2001) and 
production in these regions. In the constant-elasticity-of-substitution production nest, producers choose first between imported and domestic inputs according to the model's Armington (1969) elasticities, and then choose whether to use GM or nonGM intermediate inputs in their production of final goods.

Golden rice, however, requires a treatment different from other GM rice because we assume there is no net difference between producing golden rice and nonGM rice in terms of farm productivity. Since any input saving is assumed to be absorbed in the cost of segregation and identity preservation, the motivation for farmers to adopt golden rice has to come from the higher price it can attract in competition with other GM and traditional varieties, net of the extra cost of segregation and identity preservation of this superior variety.

Data on global adoption of GM technologies reveal a wide divergence in adoption across countries. In the base case simulation, we assume that 75 percent of oilseed production in the US, Canada and Argentina is GM and that 45 percent of US and Canadian and 30 percent of Argentinean rice and coarse grain production is GM. Since these countries are already GM adopters in coarse grain and oilseeds, we assume they would also be the earliest adopters of GM rice once it is ready for commercial release. Those countries' farmers have shown no interest in golden rice, so it is assumed their adoption is restricted to other GM rice varieties. In the alternative scenarios involving GM rice adoption in Asia's developing countries, we compare two cases: one in which 45 percent of the rice crop is grown with GM seed that enhances farm productivity, and the other in which 45 percent of the rice crop uses golden rice seed. The latter set of adopting farmers is assumed to be able to segregate their golden rice from other rice in order to market this product based on its

Jackson and Anderson (2004). 
enhanced nutritional composition. ${ }^{5}$ We also consider the case where Asia's developing countries adopt GM varieties of coarse grains and oilseeds that account for 45 percent of their production of those crops.

\section{Productivity shocks}

GM rice has not been commercialized yet, however around the world several varieties have been approved for field trials and environmental release. Based on field interviews with farmers and scientists, Huang, Hu, van Meijl and van Tongeren (2002) hypothesize the impacts of GM rice adoption on rice yield and input uses. While these authors focus on potential farm productivity enhancements of this GM technology, for golden rice it is necessary to capture the impact on human health and its effects throughout the economy. Zimmermann and Qaim (2003) estimate that, under conservative adoption and consumption assumptions, golden rice could lead to at least a six percent increase in DALYs. The following simulations, using a conservative approach, represent these health impacts with an assumed two percent shock to unskilled labor productivity in all sectors (and no direct impact on the productivity of skilled laborers who are assumed to be rich enough to already enjoy a nutritious diet). ${ }^{6}$ Table 1 summarizes the productivity shocks assumed when the two different types of GM rice are adopted, to capture both agricultural productivity and health impacts. In the absence of any information to the contrary, we assume golden

\footnotetext{
${ }^{5}$ The cost of segregation would be smaller, the more rice is consumed by the producing household or sold to local consumers, as is common in developing Asian countries.

${ }^{6}$ There would also be non-pecuniary benefits of people feeling healthier, and less expenditure on health care, but these are ignored.
} 
rice production is neither more nor less productive in the farmers' use of factors and inputs than traditional rice net of segregation and identity preservation costs. ${ }^{7}$

While these simulations assume biased technical change in GM rice, technical change in both coarse grains and oilseeds is assumed to be Hicks-neutral. Van Meijl and van Tongeren (2002) also assume a Hicks-neutral, output-augmenting productivity shock of 5 percent for coarse grains, but for soybeans they assume a chemical- and labor-productivity shock. Alternative simulations were conducted to assess the importance of these assumptions concerning biased technical change, but because the welfare results are not substantially different we retained the simpler Hicks-neutral assumption. ${ }^{8}$

The simulations reported here are conservative estimates of the impacts of the adoption of golden or other GM rice in that they assume only 45 percent adoption. This captures the impact in the medium term rather than the potential impacts of full adoption in the long term. In addition, the two percent unskilled labor productivity shock assumes only one-third of the long-run lower-bound estimate of the labor productivity impacts estimated by Zimmerman and Qaim (2002).

\section{Consumption}

In order to capture consumer aversion to GM products in some OECD countries, elasticities of substitution between GM and non-GM products in those

\footnotetext{
${ }^{7}$ Zimmermann and Qaim (2002, p. 21) report that breeders do not expect the presence of beta-carotine in golden rice to have any adverse agronomic impact on its production relative to current non-GM rice varieties.

${ }^{8}$ The results from sensitivity analysis are available from the authors.
} 
regions are set at low levels. ${ }^{9}$ Once golden rice is introduced, consumers in developing Asia are assumed to have a preference for it over other rice. For simplicity and to continue to be conservative, we ignore the possibility that consumers of inferior grains might shift to golden rice and instead just represent the consumer response as involving demand for non-golden rice shrinking by 45 percent so that golden rice accounts for 45 percent of total rice demand in adopting countries. And since developing Asian countries are only very slightly different from $100 \%$ rice selfsufficient, we assume the consumer health benefit of golden rice is confined to the adopting countries.

\section{Factor ownership}

GTAP provides a comprehensive decomposition of changes in national economic welfare as measured by the equivalent variation in income. National measures of welfare changes hide the distributional implications within countries of GM adoption and trade policy responses, however, and thus fail to provide insights into the political economy of GM policy choices. While the total economic benefits from trade typically decrease when inefficient policies such as import bans are implemented, some groups within national economies will benefit. Hence further analysis of the intra-national distribution of effects of adoption by some countries and of policy reactions by other countries is desirable.

We examine the effects on intra-regional distribution of income by dividing the economy into three groups of households: farmers, unskilled laborers, and owners of human and other capital. Income of each group comes from a combination of

\footnotetext{
${ }^{9}$ Elasticities of substitution are included in the computation of the distribution of GM and non-GM consumption of coarse grains, oilseeds, and rice within each region. Systematic sensitivity analysis
} 
factors. Farm households earn income from farm and non-farm activities. The existing GTAP database provides information about the availability and use of land, unskilled labor, skilled labor, other natural resources and other capital in the agricultural sector, and likewise in other sectors. Non-farm activities of farm households are assumed to earn income from factors in the same proportion as activities conducted by the typical urban capital-owning household. Hence factor shares for farm households are a weighted sum of factor shares used in agricultural production and the factor income shares of capital owners. The shares of farm household income from non-farm activities are assumed to be 90 percent in Japan and Korea, 50 percent in China and the EU, 35 percent in US and Canada, 25 percent in Australia, New Zealand, and Eastern Europe, and 20 percent in all Latin American countries, India, South and South-east Asia, South African Customs Union and the rest of the world. The remaining Sub-Saharan African countries are assumed to gain 10 percent of their farm household income from non-farm activities. Unskilled laborers are assumed to receive all their income from unskilled labor. In the absence of sufficient national household surveys we simply assume the expenditure shares are the same for all households within each country, so real household incomes are calculated by deflating by the national consumer price index. The use of the CPI to capture changes in consumer expenditure underestimates the impact of GM crop adoption on poor Asian farmers and unskilled laborers who spend a relatively large proportion of their income on food. 


\section{Scenarios and results}

Two sets of simulations are compared to the base case to explore the national, regional and global impacts of GM rice adoption in Asia. The first set assumes that the US, Canada and Argentina have adopted GM coarse grains and oilseeds (but not rice). This is modelled as a Hicks-neutral productivity shock on the GM varieties to capture their higher productivity. The simulations in this first set are:

Sim 1: US, Canada and Argentina adopt GM coarse grains and oilseeds (farm productivity shock);

Sim 2: As for Sim 1 + China, South and Southeast Asian countries adopt golden rice (rice demand/supply and unskilled labor productivity shocks);

Sim 3: As for Sim 2 + EU-15, Japan and Korea impose a ban on imports of rice (and coarse grains and oilseeds) from countries adopting GM varieties of those crops (trade policy response shock).

The second set of simulations assume that the US, Canada and Argentina join developing Asia in adopting GM non-golden rice, modelled as a factor productivity shock on the GM varieties to capture their higher farm productivity. Thus:

Sim 4: As for Sim $1+$ China, South and Southeast Asia as well as the US, Canada and Argentina adopt non-golden GM rice (farm productivity shock);

Sim 5: As for Sim $4+$ China, South and Southeast Asia also adopt GM coarse grains and oilseeds (extra farm productivity shock); 
Sim 6: As for Sim 5 + EU-15, Japan and Korea impose a ban on imports of rice, coarse grains and oilseeds from countries adopting GM varieties of those crops (trade policy response shock).

The estimated national economic welfare effects of these shocks are summarized in Table 2. Assuming no adverse reaction by consumers or trade policy responses by governments, the first column shows that the adoption of GM varieties of coarse grains and oilseeds by the US, Canada and Argentina would have benefited the world by almost US $\$ 2.3$ billion per year, of which $\$ 1.3$ billion is reaped in the adopting countries. Asia and the EU enjoy most of the rest, through an improvement in their terms of trade, as net importers of those two sets of farm products. The only losers in that scenario are countries that export those or related competing products. Australia and New Zealand lose because their exports of grass-fed livestock products are less competitive with now-cheaper grain-fed livestock products in GM-adopting countries.

Column 2 of Table 2 shows the projected gains from golden rice adoption by developing Asia. They are almost seven times the gains in Simulation 1 from GM maize and oilseed adoption in the Americas, amounting to an extra $\$ 15.2$ billion per year globally (over and above the $\$ 2.3$ billion benefit from prior GM maize and oilseeds adoption in the Americas). All but one-eighth of those projected gains stay in the Asian countries adopting golden rice. The sources of their gains are revealed in Table 3. Most of the gains come directly from the enhanced productivity of unskilled labor, while about 15 percent of their gains are due to improved efficiency of national resource use given the presence of price-distorting policies in the adopting countries. Adopting countries experience a slight worsening in their terms of trade. 
Table 3 also reveals that this technology would boost real incomes of farm households by 0.9 percent in China and by about 0.4 percent in Asia's other developing countries, and of households dependent solely on unskilled wage earnings by 0.7 percent in China, 0.3 percent in India, and 0.5 percent in other South and Southeast Asia. Other households in those countries also gain, so as a share of GDP the welfare gain is equivalent to 2 percent for China and 0.5 percent for other developing Asia. The GDP boost from this golden rice technology makes developing Asia more affluent, which expands its demand for exports from the rest of the world, so all other regions gain as well through improved terms of trade, although only slightly relative to the percentage gains to the adopting countries.

The first two of these simulations assume there is no adverse consumer or policy reaction in countries to whom the GM adopters export. If instead the EU, Japan and Korea were to place a ban on imports of these products from the GM-adopting countries (as indeed the EU has been doing since 1998 through a de facto moratorium on the authorization of new releases of GMOs), Simulation 3 in Table 2 shows the global welfare gains are diminished markedly. An examination of the distribution of those changes in welfare reveals that the benefit to the American adopters of GM maize and oilseeds is reduced by one-quarter, whereas the benefit to the Asian adopters of golden rice does not fall at all (in fact it rises slightly). The latter is mainly because those countries are and remain almost 100 percent self-sufficient in rice and do not export much rice to the moratorium countries because of those countries' high tariffs on rice imports. Also, developing Asia gains very slightly from a reduction in the price of their imports of maize and oilseeds from America. The biggest losers economically from the moratorium are of course the countries imposing the import ban, against which needs to be weighed the value they place on the certainty of not 
importing GMOs following GM adoption abroad. The rest of the world gains from the moratorium, including Sub-Saharan Africa and the rest of Latin America, either because they are able to import these products more cheaply from the GM-adopting countries or because they are able to export non-GM varieties of those crops to the moratorium countries and receive higher prices than previously (assuming they can verify that their produce is GM-free).

How do these results for golden rice compare with the gains that would come from adopting GM rice varieties aimed solely at enhancing farm productivity? Assuming the farm productivity gains reported in column 1 of Table 1 were achievable, the welfare effects of introducing non-golden GM rice in developing Asia (and in North America and Argentina) are shown under Sim 4 in Table 3. When compared with Sim 1 (just American adoption of GM maize and oilseeds), the addition of rice in those countries and in developing Asia almost doubles the global welfare gain (from $\$ 2.3$ to $\$ 4.4$ billion per year). If that prompted developing Asia to also adopt GM varieties of coarse grains and oilseeds, the global gains would rise to $\$ 4.9$ billion (Sim 5 in Table 2). Simulations 4 and 5 assume no policy reactions abroad. Sim 6 in Table 2 estimates the outcome if the EU, Japan and Korea were to ban imports of those products from GM-adopting countries. In that case, so large is the cost of protection to those import-banning countries that the world economy is worse off than without any GM adoption. But notice again that that moratorium would not alter very much the welfare gain to developing Asia, for similar reasons to the golden rice case. More importantly, though, the impact on welfare in developing Asia, even when GM adoption in Asia spreads to coarse grains, oilseeds and nongolden rice, is nowhere near as great as with the adoption of golden rice. 


\section{Conclusions}

From the viewpoint of Asia's developing countries, the above results are good news in a number of respects. First, the GM crop technology promises much to the countries willing to adopt these new varieties. The first-generation, farm-productivity enhancing GM varieties alone will boost welfare in the adopting countries, and more so if adoption extends beyond rice to maize and oilseeds, even if rich countries impose a ban on imports of affected crop products from the adopting countries. And those welfare gains will contribute towards alleviating poverty directly in those countries through boosting the real household incomes of both farmers and unskilled laborers.

Second, and of potentially even greater significance in terms of national welfare gains and poverty reduction, is the prospect of adopting golden rice. Assuming the estimated health/labor productivity gains reported in Zimmerman and Qaim (2002) are reliable, substantial welfare gains are expected even based on conservative assumptions regarding adoption rates and assuming that golden rice has no positive effect on farm productivity (other than through the unskilled labor effect which impacts on all sectors in the adopting countries). Moreover, we include no valuation of the non-pecuniary welfare gain to VAD sufferers from being able to reduce that vitamin deficiency through access to golden rice. If other developing countries, particularly in Sub-Saharan Africa, also adopted goldern rice, the welfare gains and alleviation of poverty and ill-health would be even greater. The gains would be greater still if golden rice adoption encouraged the adoption of other GM rice and other crop varieties. 
The stakes are thus very high. Developing Asian countries need to assess whether they share the food safety and environmental concerns of the Europeans regarding GMOs. If not, their citizens in general, and their poor farmers, unskilled workers and VAD sufferers in particular, have much to gain from adopting GM rice. The welfare gains from GM crop adoption by developing Asian countries would not be jeopardized by rich countries banning imports of those crop products from the adopting countries. This is particularly so wherever rich countries maintain high rice tariffs, since those barriers ensure virtually no rice is imported by those countries anyway. ${ }^{10}$

\footnotetext{
${ }^{10}$ For an analysis of the impact of protection policies on the benefits of adopting GM varieties, see
} Anderson and Nielsen (2004). 


\section{References}

Anderson, K. and C.P. Nielsen (2004), 'Economic Effects of Agricultural Biotechnology Research in the Presence of Price-distorting Policies', Journal of Economic Integration 19(2), June (forthcoming).

Armington, P.A. (1969), 'A Theory of Demand for Products Distinguished by Place of Production', IMF Staff Papers 16: 159-178.

Beyer, P., S. Al-Babili, X. Ye, P. Lucca, P. Schaub, R. Welsch and I. Potrykus (2002), 'Golden Rice: Introducing the Beta-Carotene Biosynthesis Pathway into Rice Endosperm by Genetic Engineering to Defeat Vitamin A Deficiency', Journal of Nutrition 132: 506-10.

Bouis, H.E. (2000), 'The Role of Biotechnology for Food Consumers in Developing Countries', pp. 189-213 in Agricultural Biotechnology in Developing Countries: Towards Optimizing the Benefits for the Poor, edited by M. Qaim, A.F. Krattiger and J. Von Braun, Dortrecht: Kluwer.

Brookes, G. and P. Barfoot (2003), 'GM Rice: Will This Lead the Way for Global Acceptance of GM Crop Technology?’ ISAAA Briefs No. 28-2003, Cornell University, Ithaca.

Dawe, D., R. Robertson and L. Unnevehr (2002), 'Golden Rice: What Role Could it Play in Alleviation of Vitamin A Deficiency?' Food Policy 27: 541-60.

Dimaranan, B.V. and R.A. McDougall (eds.) (2002), Global Trade, Assistance, and Production: The GTAP 5 Data Base, West Lafayette: Center for Global Trade Analysis, Purdue University.

Frisvold, G. (1997), 'Multimarket Effects of Agricultural Research with Technological Spillovers,' Chapter 13 in Global Trade Analysis: Modeling and Applications, edited by T. Hertel, Cambridge and New York: Cambridge University Press.

Harrison, W.J., J.M. Horridge and K.R. Pearson (1996), 'Decomposing Simulation Results with Respect to Exogenous Shocks', Working Paper No. IP-73, Centre of Policy Studies and the IMPACT Project, Monash University, May.

Harrison, W.J. and K.R. Pearson (1996), 'Computing Solutions for Large General Equilibrium Models Using GEMPACK', Computational Economics 9: 83172.

Hertel, Thomas W. (ed.) (1997), Global Trade Analysis: Modeling and Applications, Cambridge and New York: Cambridge University Press.

Huang, J., R. Hu, H. van Meijl and F. van Tongeren (2002), 'Biotechnology Boosts to Crop Productivity in China: Trade and Welfare Implications,' mimeo, Center for Chinese Agricultural Policy, Chinese Academy of Sciences, Beijing.

Jackson, L.A. and K. Anderson (2004), 'Why Are US and EU Policies Toward GMOs So Different?' AgBioForum 7 (forthcoming).

van Meijl, H. and F. van Tongeren (2002), 'International Diffusion of Gains from Biotechnology and the European Union's Common Agricultural Policy,' Paper presented at the 5th Annual Conference on Global Economic Analysis, Taipei, Taiwan.

Murray, C.J.L. and A.D. Lopez (eds.)(1996), The Global Burden of Disease, Vols. I and II, Cambridge MA: Harvard University Press for the Harvard School of Public Health on behalf of the WHO and World Bank. 
Nielsen, C.P. and K. Anderson (2001), 'Global Market Effects of Alternative European Responses to Genetically Modified Organisms,' Weltwirtschaftliches Archiv 137(2): 320-46, June.

Sommer, A. and K.P. West Jr. (1996) Vitamin A Deficiency: Health, Survival, and Vision, London and New York: Oxford University Press.

USDA (2001), Agricultural Income and Finance Outlook, ERS Report AIS-77, Washington, DC: US Department of Agriculture, 25 September.

Ye, X., S. Al-Babili, A. Kolti, J. Zhang, P. Lucca, P. Beyer and I. Potrykus (2000), 'Engineering the Provitamin A (Beta-Carotene) Biosynthetic Pathway into (Carotenoid-Free) Rice Endosperm', Science 287: 303-05.

Zimmermann, R. and M. Qaim (2002), 'Projecting the Benefits of Golden Rice in the Philippines', ZEF Discussion Paper No. 51, Bonn: Center for Development Research, September. 
Table 1: Assumed impact of GM rice adoption on factor productivity, by sector (percent change)

Adoption of non- Adoption of golden GM rice golden GM rice (impact in GM rice (impact in all

\begin{tabular}{lcc} 
& sub-sector) & sectors) \\
\hline Land & 6 & 0 \\
Skilled labor & 8 & 0 \\
Unskilled labor & 8 & 2 \\
Capital & 0 & 0 \\
Natural Resources & 0 & 0 \\
Chemical inputs & 5 & 0
\end{tabular}

Source: Authors' assumptions, based on the literature review by Huang, $\mathrm{Hu}$, van Meijl and van Tongeren (2002) for column 1, Zimmermann and Qaim (2002) for column 2. 
Table 2: Economic welfare effects of GM rice, coarse grain and oilseed adoption by developing Asia and the US, Canada and Argentina

$$
\text { (equivalent variation in income, US\$ million) }
$$

$\begin{array}{lrrrrrr} & \begin{array}{c}\text { Sim 1 } \\ \text { (base) }\end{array} & \text { Sim 2 } & \text { Sim 3 } & \text { Sim 4 } & \text { Sim 5 } & \text { Sim 6 } \\ \text { China } & 107 & 7209 & 7346 & 871 & 964 & 1001 \\ \text { India } & 0 & 2528 & 2528 & 458 & 709 & 696 \\ \text { Other South + SE Asia } & 36 & 4140 & 4143 & 671 & 760 & 781 \\ \text { Japan and Korea } & 322 & 718 & -1637 & 429 & 486 & -6306 \\ \text { USA + Canada } & 1011 & 1314 & 782 & 1035 & 1021 & 539 \\ \text { Argentina } & 312 & 314 & 218 & 318 & 314 & 241 \\ \text { Other Latin America } & 89 & 130 & 865 & 93 & 89 & 910 \\ \text { Australia + New Zealand } & -14 & 4 & 96 & -18 & -21 & 132 \\ \text { EU15 } & 267 & 732 & -2766 & 314 & 338 & -3801 \\ \text { Sub-Saharan Africa } & 1 & 23 & 116 & 6 & 7 & 168 \\ \text { Rest of World } & 159 & 326 & 336 & 203 & 220 & 186 \\ \text { WORLD total } & \mathbf{2 2 9 0} & \mathbf{1 7 4 3 8} & \mathbf{1 2 0 6 0} & \mathbf{4 3 7 9} & \mathbf{4 8 8 7} & \mathbf{- 5 4 5 2}\end{array}$

Source: Authors' model results. 
Table 3: Decomposition of national economic welfare effects for Simulation 2 (NA and ARG adopt GM maize and oilseeds, developing Asia adopts golden rice) and percentage change in real household incomes of farmers and unskilled laborers

\begin{tabular}{|c|c|c|c|c|c|c|}
\hline & $\begin{array}{l}\text { TOTAL } \\
\text { welfare } \\
\text { gain, } \\
\text { due to: }\end{array}$ & $\begin{array}{l}\text { Enhanced } \\
\text { allocative } \\
\text { efficiency }\end{array}$ & $\begin{array}{l}\text { Change } \\
\text { in terms } \\
\text { of trade }\end{array}$ & $\begin{array}{c}\text { Enhanced } \\
\text { productivity } \\
\text { of Asian } \\
\text { unskilled } \\
\text { labor or } \\
\text { American } \\
\text { farms } \\
\end{array}$ & $\begin{array}{c}\text { Farm } \\
\text { h'hold } \\
\text { income } \\
(\% \\
\text { change })\end{array}$ & $\begin{array}{c}\begin{array}{c}\text { Unskille } \\
\text { d laborer } \\
\text { income } \\
(\% \\
\text { change })\end{array}\end{array}$ \\
\hline China & 7209 & 1288 & -379 & 6268 & 0.89 & 0.65 \\
\hline India & 2528 & 408 & -143 & 2267 & 0.42 & 0.28 \\
\hline Other Sth + SE Asia & 4140 & 466 & -425 & 4110 & 0.37 & 0.49 \\
\hline Japan and Korea & 718 & 189 & 568 & 0 & 0.02 & -0.02 \\
\hline USA + Canada & 1314 & 160 & -198 & 1304 & -0.70 & 0.04 \\
\hline Argentina & 314 & 21 & -50 & 338 & -0.05 & 0.05 \\
\hline EU15 & 732 & 353 & 422 & 0 & -0.02 & -0.02 \\
\hline Sub-Saharan Africa & 23 & 14 & 9 & 0 & -0.01 & -0.07 \\
\hline
\end{tabular}

Source: Authors' model results. 